\title{
EMOCIONES, OFENSA Y REGISTRO SOCIOLINGÜÍSTICO: EL CASO DE LOS “USOS DISTANTES” DE LOS TÉRMINOS DISCRIMINATORIOS
}

\author{
JUSTINA DiAZ LEGASPE \\ IIF-SADAF-CONICET \\ Western University \\ jlegaspe@uwo.ca \\ ROBERT STAINTON \\ Western University \\ rstainto@uwo.ca
}

RESUMEN: Existe un tipo particular de usos de términos discriminatorios en el que las emociones negativas típicamente asociadas a él (odio, enojo) no se hallan de hecho presentes. Aun así, lo incorrecto o inadecuado sigue resonando en esos usos. Este tipo de "uso distante" resulta interesante per se, en cuanto fenómeno conversacional rara vez advertido. Sin embargo, también presta apoyo a una aproximación a los términos discriminatorios basada en el concepto sociolingüístico de "registro", de la cual se sigue esta relación entre emociones e incorrección. Este trabajo examina algunos tipos de usos distantes y sus rasgos esenciales, y considera cómo el registro sociolingüístico de los términos discriminatorios puede dar cuenta de ellos.

PALABRAS CLAVE: significado, semántica, teorías del significado, discriminación, ofensa lingüística

SUMMARY: There is a particular kind of use of slurs in which the negative emotions typically associated with them (hatred, anger) are not present in the occurrence. Even so, these uses still resonate as incorrect or inadequate. This kind of "detached use" is not only an interesting, rarely mentioned phenomenon per se; it also offers some support to a novel approach to slurs based on the sociolinguistic notion of "register". This paper examines some types of detached uses, extracts some of their essential features and assesses the way the register-based approach to slurs can account for them.

KEY WORDS: meaning, semantics, theories of meaning, discrimination, linguistic offense

\section{Introducción}

Sin duda, los términos discriminatorios son fascinantes, y por ello han atraído la atención de estudiosos de diferentes disciplinas: lo son desde una perspectiva ética o psicológica, bajo la lupa de la 
semántica o como fenómenos sociales, por ejemplo. ${ }^{1}$ Tal vez por eso, desde hace poco más de una década, este tipo de términos ha ganado también interés entre los filósofos y, más concretamente, entre los filósofos del lenguaje. ${ }^{2}$ Tal es así que la bibliografía obligatoria para una comprensión cabal del significado y uso de estos términos ha crecido al punto de ser imposible aprehender su polifacética riqueza en la lectura de un solo artículo, incluso de un solo libro.

Por eso, en este artículo, nos hemos planteado metas modestas, casi mínimas: el lector encontrará en estas páginas nuestro intento de alcanzar solamente tres objetivos. En primer lugar, nos proponemos llamar la atención sobre un uso sociolingüística y filosóficamente intrigante de términos discriminatorios como "bolita", "puto" y "retrasado", un uso que llamaremos "distante" por razones que quedarán claras enseguida. Este tipo de usos se caracterizan por dos rasgos gemelos: por un lado, resulta claro en ellos que las emociones negativas asociadas al uso típico de estos términos están ausentes en el hablante. Por otro lado, y a pesar de esta ausencia, estos usos siguen resultando chocantes; dejan, por decirlo así, un mal sabor de boca, el resabio de haber dicho algo malo. Los usos distantes protagonizan, entonces, este artículo. En segundo lugar, ensayaremos un acercamiento a estos usos basado en el concepto sociolingüístico de "registro", una herramienta que, creemos, la filosofía del lenguaje no ha tenido lo suficientemente en cuenta. ${ }^{3}$ En tercer lugar, señalaremos, de pasada, puntos de interés relativos al vínculo entre emociones negativas y ofensa, en particular entre aquellas desencadenadas por el uso de estos términos.

Nuestro objetivo es enteramente positivo: nos damos por más que satisfechos con poner sobre la mesa una explicación de por qué los usos distantes de los términos singulares exhiben la desconexión mencionada. Por supuesto, existen explicaciones alternativas a la nuestra que el lector quizá ya tenga en mente; sin embargo, nuestro objetivo no es confrontar estas otras explicaciones ni probar que nuestro

${ }^{1}$ Dado el tema que nos compete, nos vemos obligados a citar y mencionar innumerables palabras y expresiones cuyo uso condenamos. Pedimos disculpas de antemano; sepan que no es nuestra intención herir los sentimientos de nadie. A fin de generar el menor impacto posible, usamos los ejemplos menos ofensivos que encontramos allí donde pudimos elegir.

${ }^{2}$ Entre otros, Anderson y Lepore (2013a y 2013b), Camp (2013), Croom (2011), Hom $(2008,2010,2012)$ y Hom y May (2013 y 2018), Hornsby (2001), Jeshion (2013a y 2013b), Potts (2007), Schlenker (2007), Whiting (2013) y Williamson (2009). Una postura similar a la nuestra puede hallarse en Pullum 2018.

${ }^{3}$ Con excepción de Predelli 2013. Hallamos también posturas algo cercanas a nuestro uso del registro en Nunberg 2018, y en Anderson y Lepore 2013a y 2013b. 
acercamiento es el mejor. Si las mencionamos, es sólo para clarificar nuestro acercamiento basado en el registro y contrastarlo con teorías más habituales. Nuestro interés radica en mostrar cómo la noción de "registro" ayuda a resolver problemas de una manera sencilla.

El logro de estos tres objetivos requiere una serie de pasos. En la primera sección esclareceremos lo que queremos decir con "términos discriminatorios" (slurs), partiendo de las definiciones ofrecidas en la literatura sobre el tema, pero basándonos en nuestras propias intuiciones, que esperamos que el lector comparta. Asimismo, introduciremos con más detalle los usos que hemos dado en llamar "distantes" a través de una serie de ejemplos que ilustran con mayor o menor claridad los rasgos gemelos que consideramos tan intrigantes. En la segunda sección esbozaremos las bases de un acercamiento reciente a los términos discriminatorios basado en la noción sociolingüística de "registro".4 Ello exigirá, desde luego, aclarar en qué consiste dicha noción. Con ella sobre la mesa avanzaremos en su aplicación a usos "distantes" de los términos discriminatorios, con la esperanza de que el resultado conduzca a apreciar cómo se forja la relación entre ofensa y emoción, y cómo los usos distantes se siguen naturalmente de esta alternativa teórica.

\section{Usos "distantes" de términos discriminatorios}

\subsection{Sobre los términos discriminatorios}

Quien dijo que las palabras se las lleva el viento y que lo que pesa son los hechos, sin duda no tuvo en cuenta el impacto que ciertas palabras tienen en quien las recibe, especialmente cuando se trata de un individuo o un grupo particularmente vulnerable. En rigor, las palabras pueden resultar tan traumáticas como los golpes. Por supuesto, el sentido proposicional de lo dicho es en gran parte responsable del impacto: lo que aseveramos puede dañar a nuestros interlocutores (aun cuando no sea ésa nuestra intención). Sin embargo, también resulta dañino el modo en que lo decimos, la manera en que nos hablamos y nombramos. Entendemos que los "términos discriminatorios" se alinean con esta segunda manera de dañar, ${ }^{5}$ con cómo decimos las cosas más que con lo que afirmamos.

¿Qué son específicamente estos términos discriminatorios? En primer lugar, se trata de palabras, aisladas o aunadas en expresiones

\footnotetext{
${ }^{4}$ Véase Diaz-Legaspe, Liu y Stainton 2020.

${ }^{5}$ Esto nos aleja de propuestas semanticistas como las de Hom $(2018,2010,2012)$, y Hom y May (2013 y 2018).
} 
complejas, y no de las acciones llevadas adelante por su uso. Un acto discriminatorio, es sabido, se puede llevar a cabo tanto a través del uso del lenguaje como sin él. Además, los actos discriminatorios que sí se realizan a través del uso del lenguaje no necesariamente apelan a términos discriminatorios: cada palabra de la frase "No alquilamos habitaciones a inmigrantes", por ejemplo, es perfectamente aceptable, aun cuando la emisión de la misma constituya un acto discriminatorio. Los términos discriminatorios que nos competen, en cambio, son aquellas palabras que resultan potencialmente ofensivas en virtud de su significado estable (u otros rasgos ligados al mismo). Así, la emisión de "Aquí no aceptamos maricones" constituye un claro acto lingüístico discriminatorio, pero, además, a diferencia del ejemplo anterior, contiene una palabra cuando menos cuestionable en virtud de su significado: "maricón", término discriminatorio para hombres homosexuales.

Los términos discriminatorios pertenecen a la bolsa de gatos a la que solemos llamar "insultos" o "malas palabras", que incluye vulgaridades, descripciones ofensivas, obscenidades y blasfemias, entre otros. Los términos discriminatorios resaltan de entre todos ellos por afectar a grupos enteros de individuos, y no solamente al individuo receptor. Se trata de términos que refieren a grupos $-\mathrm{o}$ a individuos en virtud de su pertenencia - típicamente marginados o vulnerables. ${ }^{6}$ Diferentes culturas y regiones tienen palabras discriminatorias para los grupos signados por raza, etnia, nacionalidad o estatus migratorio, inclinación sexual o género que son marginados en su estructura sociopolítica. En castellano encontramos "bolita" (en Argentina, término despectivo para bolivianos), "puto" (común en países de habla hispana para denostar a hombres homosexuales o con rasgos asociados al estereotipo local de feminidad), "retrasado" (usado para referirse a personas con capacidades cognitivas diferentes), "mongólico/mogólico" (peyorativo para personas con síndrome de Down en Argentina) o "sudaca" (en España, despectivo para inmigrantes latinoamericanos o latinoamericanos en general). En inglés los ejemplos abundan: "kike" es usado para referirse a judíos, "dyke" para mujeres homosexuales y "coon" que se aplica a individuos de raza negra. No abrumaremos al lector con más ejemplos; basta una muestra para entender a qué términos nos estamos refiriendo.

\footnotetext{
${ }^{6}$ Con más precisión, se trata de términos referenciales para grupos inmersos en una relación de marginación u opresión. Así, incluimos en la categoría a los términos discriminatorios "retaliativos" como "yanqui" o "gringo", usadas por grupos marginados para referirse a sus opresores.
} 
Este conjunto de términos posee varios rasgos comunes que han llamado la atención de lingüistas y filósofos del lenguaje en la última década. Para el propósito de este artículo nos centraremos sólo en algunos de ellos:

1. Nombran grupos marginados y vulnerables: se trata de palabras usadas por una comunidad de hablantes para referirse a un conjunto de individuos del que los primeros no forman parte, que poseen un determinado rasgo común que en sí mismo no amerita una actitud negativa. ${ }^{7}$

2. Su uso está asociado prototípicamente a la posesión y expresión de emociones negativas: al hablante que usa estos términos se le suelen atribuir emociones como odio o enojo, o actitudes negativas complejas (como el desprecio) hacia la totalidad del grupo al que los dirige.

3. Su uso es considerado ofensivo: su uso es considerado potencialmente ofensivo por personas de bien que de ninguna manera usarían términos de este tipo. No se trata efectivamente de que ofendan a quienes se ven expuestos a ellos, sino de que, en casos prototípicos de uso, ofenderse está justificado tanto en quien los recibe como en terceros que los escuchan, así como en los individuos integrantes del grupo afectado, sean o no parte de la conversación. Apelar en este punto a una reacción subjetiva como la ofensa puede sembrar confusión. A modo de aclaración, no se trata de que quienes escuchan se sientan o deban de hecho sentirse ofendidos, sino que sentirse ofendido está socialmente justificado, a diferencia de, digamos, sentirse ofendido por una reseña negativa, aunque correcta y justa.

Examinemos la emisión de 1 para apreciar estos rasgos:

1) Ahí viene el retrasado.

"Retrasado" es un término despectivo que se utiliza para dirigirse o hablar peyorativamente de personas con discapacidad cognitiva, un

${ }^{7}$ No vamos a ahondar aquí en la potencial objeción de que el hecho de que "merecer una actitud negativa" es relativo a una comunidad. Queremos simplemente apelar al contraste intuitivo entre grupos cuyo rasgo determinante consideramos neutro, y grupos cuyo rasgo determinante consideramos merecedor de trato diferencial negativo, como "ser pedófilo". Para una consideración más detallada de "neutralidad" en grupos, véase Diaz-Legaspe 2020. 
grupo, lamentablemente, marginado, estigmatizado y socioeconómicamente vulnerable en la mayoría de las culturas. Debería quedar claro para todos que nadie con estas características merece otra cosa que respeto y trato inclusivo.

Sin ningún detalle sobre el contexto de emisión de 1 , sin información alguna acerca de quién la emite o a quién se dirige, tendemos a asumir que el emisor alberga sin duda actitudes discriminatorias no sólo contra el receptor, sino contra la comunidad entera de personas con capacidades cognitivas diferentes. Asumimos también que se emite 1 con la intención de expresar públicamente esta actitud, probablemente con la intención secundaria de herir los sentimientos del receptor.

Por último, consideremos el impacto que una emisión prototípica de 1 - esto es, una emisión realizada con la intención de expresar actitudes negativas - puede tener en el auditorio. En primer lugar, la persona a quien se dirige 1 puede sentirse herida u ofendida. Es más: aun cuando no se sienta afectada por el término, tiene un permiso social implícito a sentirse de esa manera y reaccionar en consecuencia. Pero, en segundo lugar, personas con idénticas características pueden sentirse afectadas por igual, y pueden tener tanto derecho como la primera a protestar o reaccionar. Por último, también el público bien pensante tiene derecho a sentirse ofendido y considerar que 1 es una emisión insultante y oprobiosa.

Estas tres propiedades caracterizan los usos prototípicos de los términos discriminatorios. Pero, como ya dijimos, no están presentes en todos los usos de estos términos. En especial, no están presentes en los usos no prototípicos a los que llamaremos "distantes".

\subsection{Nuestros "usos distantes"}

Antes que explicar estos usos es mejor comenzar por mostrarlos. ${ }^{8}$ En todos los casos, estos usos se distancian de alguno de los rasgos asociados a los usos prototípicos.

\section{A. Distanciados del blanco usual}

Los términos discriminatorios suelen referirse a un grupo vulnerable. En contexto, se pueden usar para dirigirse tanto al grupo como a individuos pertenecientes al mismo, o para hablar de ellos. Sin embargo, en algunos casos el hablante puede aplicar el término para

\footnotetext{
${ }^{8}$ Presentamos una categorización de los casos con el fin de resaltar características similares e imponer cierto orden, pero no debe inferirse nada sustancial de esta categorización.
} 
referirse o dirigirse a un individuo que no pertenece a ese grupo referencial:

- Ignacio vive en Toronto. Viajando en autobús escucha una conversación en la que un turista italiano habla peyorativamente de los latinos. Airado, al bajarse en su parada le grita "Spic!" ("sudaca") al hablante italiano.

- Un árabe aborda un taxi en Nueva York. El taxista, estadounidense, le dice: "Nigger, I'm not driving you." ("Negro, no pienso llevarte." $)^{9}$

B. Usos distanciados de la emoción usual

Los usos prototípicos de términos discriminatorios permiten inferir, en el hablante, emociones o actitudes negativas contra el grupo afectado. Sin embargo, en ocasiones, estos términos se usan para expresar emociones diferentes, o no permiten inferir emoción alguna en el hablante.

B.1. Términos usados en forma intencional pero con una actitud positiva:

\section{B.1.1. Usos incompetentes}

- Ramiro, un niño de 3 años, vuelve contento del jardín de infantes y al llegar anuncia que la pasó muy bien jugando con su amigo "el bolita".

- Chen, recién llegado de China a Nueva York y no enteramente competente en el inglés, le dice a su amigo "I'm excited to get to know the biggest kike community in the world" ("Estoy ansioso por conocer la comunidad de 'judíos de mierda' más grande del mundo.")

\section{B.1.2. Usos competentes}

- Reconsideremos la emisión de 1 bajo una nueva luz: aunque no es una práctica habitual, Giselle e Hilde acuerdan llamarse "retrasada" una a la otra, y llegan a saludarse con emisiones de 1. En esta reconsideración imaginamos que Giselle e Hilde son personas con capacidades cognitivas diferentes que han recibido

${ }^{9}$ Adaptación del ejemplo de Jeshion 2013a. 
este epíteto de personas malintencionadas, y que eligen ahora apropiárselo, hacerlo suyo. ${ }^{10}$

- Noah es un homofóbico acérrimo. Sin embargo, una noche en que una pareja homosexual lo ayuda a resolver un problema, anuncia: "Quién iba a decir que los putos eran tan buena gente."

\section{B.2. Usos intencionales pero forzados}

Los usos considerados hasta ahora son intencionales y producto de la libre elección de palabras por parte de los hablantes; sin embargo, el hablante podría usar la palabra en forma intencional pero coercitiva, cuando preferiría no hacerlo:

- En la Corte, Juan explica por qué su ex jefe era mal visto en el trabajo: "Lo escuché aseverar que la culpa del desempleo en el país son los bolitas."

- La policía le pide a Larissa que reproduzca literalmente lo que sus atacantes afirmaron para asentarlo en un acta. Ella dice: "Todas las mujeres son putas."

- María está en un programa de televisión que busca avergonzar a los participantes. El conductor le pide que describa al presidente de México con una palabra que rime con "maraca". María dice "sudaca".

- Oscar creció en una comunidad antisemita, y carece de términos no despectivos para referirse a los miembros de la comunidad judía, de modo que usa "kike" cada vez que se refiere a ellos. Él mismo, empero, no tiene ninguna actitud negativa contra ellos.

Los usos distantes de términos discriminatorios nos resultan interesantes justamente porque, a pesar de ser tan frecuentes, se alejan de los usos prototípicos en sus rasgos característicos. Está claro que un auditorio informado de los detalles de la emisión no inferiría que el hablante tiene actitud negativa alguna contra el grupo afectado, ni

${ }^{10}$ Uno de los árbitros de la revista tuvo a bien mencionarnos la importancia del concepto de "anticortesía" como refuerzo de la idea de que, en muchos casos, los hablantes recurren a términos vulgares sin intención de ofender, sino, más bien, como marca de cercanía entre los interlocutores. Para más detalles sobre este concepto pueden consultarse Labov 1972, Zimmerman 2003, Bernal 2008, y Mugford 2008. Agradecemos la sugerencia bibliográfica. 
pretende expresar actitud negativa alguna (con la excepción del caso de Ignacio y el taxista). A pesar de ello, aunque el auditorio reconoce que no se trata de usos prototípicos, ni infiere que el hablante sienta odio por la comunidad afectada y reconoce incluso casos en que el hablante se ve forzado al uso o está expresando afecto, aun así, el término proferido se considera social y éticamente poco feliz. La distancia en estos usos no impide que escucharlos o decirlos nos haga sentir incómodos, si no es que ofendidos. Justamente por ello, hablantes incompetentes en este sentido, como Chen o Ramiro, son corregidos, y hablantes forzados a usarlos se sienten incómodos o avergonzados. Por supuesto, cualquier ofensa potencial ante estos usos se ve mitigada por los detalles de las circunstancias de uso: no reaccionamos de la misma manera a 1 si la emite un individuo discriminante, o si son Giselle o Hilde, ni consideramos que "puta" y "bolita" sean tan ofensivos en boca de Juan y Larissa como lo fueron en la de sus emisores originales. Ahora bien, preferiríamos que Juan y Larissa usaran eufemismos, percibimos un aura de autoagresión en el apelativo cariñoso usado entre Giselle e Hilde y, en muchas ocasiones, rechazamos los usos cariñosos de estos términos ("Te pido, por favor, que no me llames así"). Si bien es cierto que, en ciertas regiones, el uso afectivo (como apelativo cariñoso) de términos discriminatorios no es inusual, y emisiones como 1 pueden suceder entre amigos, pertenezca o no el receptor a la comunidad referencial del término, aun así, algunos interlocutores se opondrían, sean cuales fueren las intenciones del hablante. En suma, la sensación de que hay algo malo con las palabras mismas no termina de ser completamente mitigada por la buena voluntad de los hablantes que las usan de estas formas distantes.

\subsection{Recordatorio y un vistazo a lo que sigue}

Nuestro primer objetivo era llamar la atención sobre este uso sociolingüística y filosóficamente intrigante, en el cual los términos discriminatorios resultan chocantes y molestos a pesar de estar distanciados claramente de la expresión de emociones negativas hacia cierto grupo típicamente asociadas a ellos. He aquí otro fenómeno digno de interés: la notoria (des)conexión entre la expresión de emociones y actitudes negativas y la ofensa.

Nuestro segundo objetivo es presentar las bases de una teoría que, creemos, puede iluminar la razón de esta desconexión. Para ello nos volcaremos en breve al concepto sociolingüístico de "registro" aplicado a términos discriminatorios. Pero, antes de emprender la 
tarea, tal vez sea necesario aclarar qué vamos a dejar de lado, qué cosas no debería esperar el lector de nosotros.

El enfoque que nos compete en este artículo tiene un alcance muy limitado: sólo nos interesa aplicar la teoría del registro al tipo particular de uso presentado antes, del cual ni siquiera abarcaremos todos los casos de usos ofensivos con actitud negativa ausente de términos discriminatorios. En particular, no vamos a considerar aquí todos los casos que pudieran presentar este choque entre potencial ofensivo y ausencia de expresión de actitudes negativas. ${ }^{11}$ Listamos abajo, de todas maneras, algunos de estos casos que no tomaremos en consideración.

C. Usos no genuinos

\section{C.1. Errores y lapsus}

- Cuando le preguntan a Patricia cómo fue el cumpleaños de Liana, dice "Estuvo muy bien, decoramos la sala con adornos de Mickey Mouse y globos de puto" (queriendo decir "Pluto").

C.2. Discurso no serio (usos "decolorados" (etiolations) en el sentido de Austin) ${ }^{12}$

- Dania está aprendiendo inglés. Para practicar pronunciación de la letra "k", recita una lista de palabras: "Mike, tyke, spike, kike".

- El actor Calvin ensaya las líneas que deberá decir en su papel en la obra Huckleberry Finn, y en ellas aparece la palabra "nigger".

${ }^{11}$ La combinación de ambos rasgos no es exclusiva del uso distante de términos discriminatorios, ni siquiera del uso del lenguaje: es un fenómeno que puede observarse en numerosas conductas humanas. Así, existen muchos casos en las inmediaciones de los usos distantes, pero estos casos, así como las relaciones entre ellos y con los casos en los que sí nos centraremos, son material para otro artículo.

${ }^{12}$ En su obra de 1962, Austin usa el término "etiolations" para referirse a un tipo de usos peculiares, parasíticos de su uso normal. En la página 22 de esta obra en su edición original en inglés leemos: "Language in such circumstances is in special ways - intelligibly - used not seriously, but in ways parasitic upon its normal use - ways which fall under the doctrine of the etiolations of language" (las negritas son nuestras). En la traducción al castellano de Genaro Carrió y Eduardo Rabossi, esta frase reza: "En tales circunstancias, el lenguaje no es usado en serio, sino en modos o maneras que son dependientes de su uso normal. Estos modos o maneras caen dentro de la doctrina de las decoloraciones del lenguaje" (p. 63). 


\section{C.3. Categoría general de menciones}

- Aaron trata de explicar a su amigo no judío el significado de "shiksa": "Les decimos 'shiksa' a las mujeres no judías, es un término despectivo."

Los reportes directos o "citas mixtas" también pertenecen a esta categoría. El uso de estos términos a modo de ejemplos quedará intacto también: muchas veces es necesario apelar a términos discriminatorios concretos. Este artículo, sin ir más lejos, los contiene de esta manera, y precisamente por ello comenzamos por disculparnos.

\section{C.4. Usos no literales}

- John Lennon usó la palabra "nigger" en su canción Woman is the nigger of the world. Sin embargo, pensar que Lennon está diciendo que las mujeres son de hecho negras sería no entender la canción. Se trata de un uso figurativo del término, donde se compara la opresión patriarcal hacia las mujeres con la opresión históricamente dirigida a las personas de raza negra.

Muchos de estos casos, si no todos, cumplen con los requisitos definitorios para ser clasificados como usos distantes: queda claro para todos que el uso (o mención) no pretende expresar desprecio u odio hacia el grupo afectado, pero aun así son usos que dejan un mal sabor de boca y son susceptibles de ser objetados. Es posible que la teoría del registro se aplique a algunos de ellos tanto como a los casos que nos competen, tal vez a todos. No obstante, consideramos que algunas de las diferencias que guardan con el grupo restringido de casos que nos competen son lo suficientemente significativas como para generar confusiones: no estamos interesados en debatir acerca del poder ofensivo de las palabras mencionadas, usadas metafóricamente o en errores del lenguaje. Todas estas aristas son lo suficientemente complejas como para que, al menos hoy, prefiramos dejarlas de lado.

En segundo lugar, no vamos a entrar en detalles ni a profundizar sobre nuestro rechazo a explicaciones alternativas de este fenómeno. Para mencionar algunas, sin elaborar, no creemos, por ejemplo, que estos casos apelen a palabras homofónicas sin carga negativa, como en el caso del término "fag" en inglés británico ("cigarrillo") o estadounidense (despectivo para homosexuales masculinos). Tampoco creemos que los usos distantes sean todos metafóricos y no literales: si bien podría argumentarse que casos de distanciamiento del grupo usual (Ignacio y el taxista) lo son, la explicación claramente no se 
extendería a los demás casos. En rigor, tampoco consideramos que todos los casos de distanciamiento del grupo habitual sean metafóricos: son a veces emisiones falsas (el término sigue refiriendo al grupo referencial habitual), más que metafóricas (en contraste con la canción de Lennon, el hablante no busca comunicar algo verdadero).

\section{El registro sociolingüistico}

\subsection{El registro y el significado uso-teórico}

El concepto de "registro" pertenece a la misma familia que otros conceptos sociolingüísticos como "dialecto" o "sociolecto". ${ }^{13}$ Todos ellos nacen de la observación de que, dada una comunidad lingüística, existen variaciones internas en el lenguaje que dependen de factores sociales. Así, individuos de diferentes regiones presentan variaciones léxicas, sintácticas o de pronunciación (dialecto), e individuos de diferentes estratos socioeconómicos o profesionales presentan variaciones en la forma en que usan el lenguaje (sociolecto). El registro corresponde a la variación del lenguaje asociada a un puñado de factores sociales que constituyen un contexto conversacional, una situación de uso del lenguaje. Los rasgos de registro, indicativos de la categoría de registro a la que pertenece una palabra, determinan el grado de propiedad de una proferencia de la misma en relación con una situación discursiva, con un tipo de conversación en un marco social establecido.

Desde nuestra perspectiva, el registro es además un subtipo de lo que llamaremos, siguiendo las líneas de pensamiento de la filosofía del lenguaje ordinario, "significado uso-teórico" y es, por lo tanto, parte del significado estable de la palabra: no comprender que la palabra posee un rasgo de registro y por consiguiente debe ser proferida sólo en contextos conversacionales específicos indica falta de competencia lingüística, es decir, falta de maestría del significadotipo y no meramente algún tipo de ignorancia del mundo. Veamos esta idea en más detalle.

En primer lugar, el lector puede encontrar confusa la idea de un "significado uso-teórico", pero un ejemplo puede mostrar hasta qué punto no se trata de nada extraño sino de un subtipo de contenido lingüístico. ${ }^{14}$ Todos los lenguajes contienen palabras o construcciones cuyo significado solamente puede darse especificando cómo se usan.

\footnotetext{
${ }^{13}$ Véanse Halliday 1973, Halliday y Matthiessen 2004, y Gregory 1967, 2001.

${ }^{14}$ Véase Stainton 1999 para una aproximación al pluralismo semántico en que nos basamos aquí. La idea de base puede rastrearse en Austin 1962.
} 
A diferencia de la palabra "mesa", cuyo significado puede darse describiendo una mesa prototípica y su función, o señalando un ejemplar de mesa, el significado de palabras o construcciones como "¡Hola!", "Bueno, bueno, ya" o "Sí, quiero”, no puede darse a través de descripciones u ostensivamente, sino indicando el tipo de acción que se suele llevar a cabo con su uso (saludar, consolar, casarse). Así, no podemos especificar sobre qué es verdadera, o a qué refiere, una palabra como "Hola". Tampoco podemos explicar cuál es el significado de estos términos señalando el estado mental, cognitivo u emotivo, que el hablante supuestamente externaliza cuando los usa: saludar no es expresar alegría o sorpresa por la llegada de alguien, ni consolar es expresar conmiseración. En todos estos casos, usar estas palabras es llevar adelante en forma pública un acto de significación social, cumplir un papel social determinado. Afirmamos entonces que este tipo de palabras tiene significado uso-teórico, amén de tener (o no) un significado veritativo-condicional.

Para el propósito de este trabajo es útil distinguir entre dos subvariedades de significado uso-teórico.

En la primera subvariedad, proporcionar el significado de las palabras o construcciones lingüísticas es indicar qué acción social lleva adelante la emisión de las mismas. Un claro ejemplo de estas construcciones son los términos fáticos, también llamados "realizativos simples": “Hola!” es usado para saludar, “Felicitaciones!” para felicitar y "Bienvenido!” para dar la bienvenida. No es casual la similitud entre estas palabras y las que describen su significado usoteórico: en condiciones adecuadas, decir la palabra es sencillamente llevar a cabo el acto. La fuerza ilocucionaria adosada a algunas palabras es otro tipo de esta subvariedad: la fuerza ilocucionaria de la interrogación, por ejemplo, sólo se puede explicar mencionando la acción de preguntar, mientras que la fuerza ilocucionaria asociada a un imperativo cumple la función de ordenar.

Existe un segundo tipo de significado uso-teórico que no se dilucida simplemente señalando la acción llevada a cabo por el uso de las palabras. Describir este segundo tipo de significado es indicar en qué situación conversacional o género discursivo encaja la palabra o construcción. Por ejemplo, pronombres que varían solamente en el grado de formalidad ("usted", "tú", "vos") se aplican en contextos conversacionales que varían en las normas que regulan la interacción de los tipos de roles que ocupan los hablantes en ellos. Lo mismo sucede con palabras que sólo usaríamos en un texto científico, o al escribir un mensaje de texto: el campo y el medio discursivo son 
algunos de los factores extralingüísticos que condicionan las palabras que elegimos usar en cada situación. El uso de los términos adecuados a la situación en la que nos hallamos y al papel que ocupamos en ellas es un tipo particular de acción social, aunque más compleja que las del subtipo anterior. En este caso, nuestro objetivo como hablantes no es llevar a cabo una acción puntual, sino decir algo, comunicar un contenido veritativo-conditional, pero hacerlo de tal manera que encaje en una práctica social, cumplir nuestro rol siguiendo las reglas que la vertebran. Por otro lado, esta acción compleja de cumplir un rol o seguir una regla tiene como consecuencia, deseada o no, la reproducción, aprobación y refuerzo implícito de la configuración social que le da base.

Una característica más de este tipo de significado uso-teórico es que, al igual que el sentido, está asociada a los tipos de palabras o construcciones, y no (solamente) a su uso. Así, de la misma manera en que el tipo de construcción "Juan fuma" tiene el significado veritativo-condicional Fumar(Juan), el tipo "usted" incluye o codifica como significado uso-teórico la indicación de que el término-tipo debe ser usado en ciertos contextos conversacionales para dirigirse a aquellos que, por edad o rango social, ocupan un nivel superior al nuestro en los mismos en muchos dialectos del castellano.

Nótese que asignar un significado relativo al modo de uso a un tipo lingüístico no implica que toda emisión ejemplifique o deba ejemplificar dicho uso. Atribuir un significado uso-teórico a un tipo es indicar el tipo de trabajo que la palabra cumple en el lenguaje. Por supuesto, no todos los usos cumplen con este dictado: los hablantes pueden (y de hecho, suelen) desviarse del modo de uso indicado por el tipo: el significado veritativo-condicional, por ejemplo, indica el tipo de condiciones de verdad que el uso de la frase podría adquirir en un contexto de uso, pero nada evita que el hablante use las mismas palabras para comunicar de una manera u otra un contenido con condiciones de verdad diferentes. Lo mismo sucede con el significado uso-teórico: aun cuando no forme parte de la función asociada al tipo "Hola" cuestionar por qué un chico llega tarde a casa, un padre podría a veces usar el término fático para hacer justamente eso. De manera similar, en las circunstancias adecuadas, un hablante podría usar "usted" para dirigirse a un viejo amigo (de igual estatus social y edad) para indicar que la amistad está en riesgo, que el amigo está siendo pedante, etc., aun cuando ninguna de estas funciones sea parte del significado uso-teórico del tipo. 


\subsection{Rasgos del registro}

El registro es parte del significado uso-teórico de algunos tipos de palabras o construcciones cuyo uso prototípico se asocia a diferentes tipos de contextos conversacionales. El registro como fenómeno sociolingüístico surge cuando, frente a un sistema de palabras codesignativas entre las que elegir, el hablante opta por aquellas marcadas por rasgos de registro que encajan en los aspectos sociales particulares de la situación de discurso. A fin de mostrar con mayor claridad en qué consisten estos rasgos de registro podemos apelar a los rasgos geométricos del estilo de Roman Jakobson. En este marco, los fonemas se caracterizan por un número restringido de cualidades que forman oposiciones binarias: cada fonema los tiene (+) o no (-). Así, el primer sonido en "vaca" es [+africativo, +estridente, -nasal, -plano, -sonoro]. De la misma manera, podemos usar $(+/-)$ para indicar los rasgos de registro que una palabra tiene o de los cuales carece. Podemos diferenciar, entonces, el rasgo [+formal] que señala que el uso de la palabra es apropiado en (tipos de) contextos formales, signados por roles jerárquicos y normas rígidas de interacción. Otro rasgo es el registro [+clínico], que indica que el uso de ese (tipo de) término o construcción es apropiado en conversaciones y textos compartidos por profesionales de la medicina. Las palabras pueden tener varios rasgos de registro, y reflejar las relaciones entre tipos de contexto. Así, los libros de medicina contienen términos con registro [+clínico, +formal] como "excremento", "hez", y no otras alternativas en el sistema de términos correferenciales como "caca", "popó" o "mierda". 15

Sin duda, lo dicho hasta ahora sobre registro trae consigo muchas preguntas. Entre ellas, por ejemplo, cuestiones sociolingüísticas, como: ¿cuál es la lista completa de las categorías de registro en, digamos, español, y cómo se relacionan entre sí? Desde una perspectiva sociológica podemos preguntarnos sobre el criterio usado para caracterizar tipos de contexto conversacionales en los que resulta adecuado el uso de términos marcados con registro [+formal], [+clínico] u

${ }^{15}$ Los rasgos de registro se adjuntan a construcciones lingüísticas o gramaticales. Sin duda, también se corresponden con situaciones mundanas. Pero sería una confusión uso/mención caracterizar una situación mundana - por ejemplo, operar a un paciente- como [+clínica, +formal]. Son las palabras específicamente destinadas a ser usadas en esa situación las que son [+clínica, +formal]. (A modo de comparación, el tiempo pasado que expresa "saltó" corresponde a un periodo anterior - en el mundo - al presente. Desde ya, la "correspondencia" rasgo-situación que sobresale no puede ser del mismo tipo que la que se da entre tiempo verbal y periodo.) 
otros. Lamentablemente, la teoría del registro no ha sido desarrollada aún lo suficiente como para poder responder estas preguntas; no nos queda más que guiarnos por intuiciones. Esto hace que nuestra aplicación de la teoría a los términos discriminatorios dependa de las respuestas que sociolingüistas y analistas del discurso den, a la larga, a estas preguntas. Reconocemos, por supuesto, que ésta es una preocupación seria, sobre todo en lo que atañe a la primera pregunta. (La segunda, en cambio, no lo es tanto: no es, en general, tarea del semántico elucidar la naturaleza de aquello que se corresponde con una oración o palabra; podemos decir lo que significan "persona" y "país" sin tener que ofrecer una teoría socio-cultural de lo que son las personas y los países. No necesitamos entonces una caracterización sociológica de los rasgos esenciales de diferentes tipos de contextos conversacionales; basta saber que el registro limita el uso adecuado de las palabras a estos tipos, haciéndolas inapropiadas o inaceptables en algunos de ellos.)

\section{Registro y palabras discriminatorias}

\subsection{El registro de las palabras discriminatorias}

Siguiendo a Diaz-Legaspe, Liu y Stainton (2020), consideramos que los términos discriminatorios se distinguen por: (i) la naturaleza de su referente - como dijimos, típicamente grupos sociales en el contexto de relaciones de marginación u opresión-, y (ii) sus rasgos de registro. Para nuestros propósitos, basta con resaltar algunos puntos esenciales de los rasgos de registro de términos discriminatorios.

Una de las facetas definitorias, a nuestro juicio, de los términos discriminatorios es el tipo de categorías de registro en las que se inscriben. No se trata simplemente de términos referenciales para grupos marginados o marginantes; se trata de maneras de referirse a esos grupos que no concuerdan con todo contexto conversacional. Por lo tanto, en lo que hace a (ii), los términos discriminatorios traen consigo tres rasgos de registro: usualmente tienen registro [+argot, +vulgar], ${ }^{16}$ y siempre tienen registro [-cortés]. Estos tres rasgos los hermanan con palabras en estas mismas categorías de registro que no son necesariamente términos discriminatorios: palabras como "mierda", "pendejo" o "chingar" tienen registro [-cortés, +vulgar], y algunas de ellas se registran también como [+argot], por ejemplo.

Hay, empero, una diferencia cualitativa entre el uso de palabras como "mierda" y palabras como "sudaca" que se refleja en el grado

16 "Mariquita" es un ejemplo de término discriminatorio que es [-vulgar, -argot]. 
de incomodidad y potencial ofensivo asociado al uso - típico o node cada una de estas palabras. En ambos casos, el auditorio puede sentirse incómodo ante la elección de palabras y, en ciertas conversaciones, se puede incluso llamar al orden al hablante. Pero con el uso de términos discriminatorios, el potencial ofensivo aumenta exponencialmente y se suma a la mera incomodidad por la elección de palabras: ya no sólo nos molesta que el hablante use un lenguaje bajo, sino que, además, consideramos sus palabras cuestionables ética, social y políticamente. Lo que explica esto es que los términos discriminatorios siempre se inscriben en una cuarta categoría de registro: tienen registro [+derogatorio]. Esta categoría, tan central para nuestra explicación como poco conocida, merece especial atención.

En primer lugar, observamos que este rasgo también puede encontrarse en términos que no son necesariamente de registro [+vulgar] ni referentes a grupos marginados. Palabras como "caranchos" o "pincharratas" (en argot argentino) son formas denigrantes de referirse a grupos no marginados: abogados y médicos, respectivamente. Decimos que son "denigrantes" con todo el peso de la palabra: su uso normal constituye un acto que denigra a todo individuo que pertenezca al grupo y lo priva de valor intrínseco e identidad por fuera de esta pertenencia. Estos términos, como los discriminatorios, tienen registro [+derogatorio].

Esto nos lleva a un segundo punto de interés. Como dijimos, el registro indica en qué contextos conversacionales deben usarse las palabras y en cuáles deben evitarse, en qué conversaciones resulta apropiado su uso en términos de su descripción sociolingüística. Sostener que ciertos términos tienen registro [+derogatorio] implica que debe haber contextos conversacionales en los que sea adecuado y esperable usar este tipo de términos. ¿De qué contextos se trata? Como pista podemos considerar casos en los que se usan palabras perfectamente ordinarias y sin marca de registro de modo despectivo, derogatorio: por ejemplo, cuando se acusa a alguien de ser "feminista", "intelectual" o "conservador". Ninguna de estas palabras es ofensiva en sí, ni su uso constituye de por sí y en todo contexto un caso de denigración. Sin embargo, se pueden usar de forma despectiva. ¿Qué caracteriza estos casos? El lector ya habrá adivinado: la intención del hablante de insultar u ofender al grupo afectado o su intención de seguirle el juego a los interlocutores que usan estas palabras a modo de insulto. De manera similar, consideramos que términos [+derogatorios] son, en función de su marca léxica, discursivamente apropiados para situaciones donde el hablante es, cuando menos, indiferente respecto de 
insultar o denigrar a grupos humanos, situaciones donde el objetivo de la conversación es denigrar a grupos humanos.

\subsection{Clarificación por contraste}

Dijimos ya que no es la intención de este artículo argumentar en contra de otras teorías acerca del significado de los términos discriminatorios. Tampoco pretendemos sostener que son incapaces de explicar sus usos distantes. Sin embargo, aun con una intención puramente positiva, contrastar algunas otras maneras de concebir los términos discriminatorios con la nuestra puede aclarar potenciales malinterpretaciones:

4.2.1. La diferencia entre la teoría basada en el registro y las teorías emotivistas

En usos prototípicos, la asociación entre términos discriminatorios, ofensa y expresión de emociones o estados mentales negativos es tan marcada que invita a considerar estos términos como artilugios lingüísticos para la externalización de estas emociones que, una vez hechas públicas, resultan ofensivas. Usaremos de forma muy laxa el nombre "emotivistas" para designar teorías comprometidas con esta idea.

Nuestro compromiso de base es radicalmente diferente: sostenemos que los significados de palabras registradas no tienen relación alguna, más que la que indicaremos enseguida, con la externalización de estado mental de ningún tipo, ni cognitivo ni emotivo. En cambio, los significados de estas palabras o construcciones conciernen directamente a la realización de una acción social. De la misma manera, la razón por la que decimos “iHola!” ante la llegada de alguien puede estar relacionada con nuestra alegría al ver a esta persona, pero aun así dar el significado de este término no implica adentrarnos en una lección de psicología. Lejos de esto, dar su significado consiste en decir que "Hola" es la palabra cuya función en castellano es saludarse.

Este compromiso deja abierta la puerta para las siguientes observaciones: para empezar, no consideramos que la función lingüística de los términos discriminatorios sea la de externalizar un estado emotivo/cognitivo. Por ejemplo, la diferencia entre "brasileño" y "brasuca" no es una emoción-a-ser-expresada por el segundo - así como tampoco es una diferencia en sentido o referencia-. La diferencia está en que el segundo está marcado por un rasgo de registro [-cortés, +derogatorio, +argot, +vulgar], mientras que "brasileño" es un término neutro. En nuestra teoría, esto significa que el uso de "brasuca" 
debería estar restringido a tipos de contextos conversacionales con ciertas características (el objetivo o aval para la denigración de otros individuos en virtud de su pertenencia a un grupo). A su vez, esto significa que el uso de "brasuca" constituye en sí mismo un acto social: encajar en este tipo particular de situación. Al usarlo, quiera o no, el hablante está reforzando el entramado social que constituye esta situación: un entramado asentado en la constitución de un grupo por medio de la oposición a otro, que avala el desprecio a individuos con base en su pertenencia a aquél.

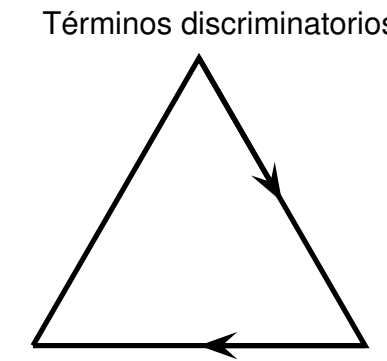

Ofensa Emociones negativas
Términos discriminatorios

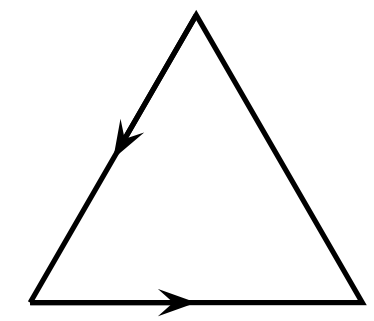

Ofensa Emociones negativas

\section{Figura 1}

Figura 2

Advertida esta diferencia, cabe aclarar que coincidimos con los emotivistas en que una de las facetas del uso prototípico de estos términos es que suelen ser las personas que albergan emociones negativas hacia el grupo afectado quienes eligen usar palabras marcadas de esta manera. Por lo tanto, hay una correlación clara e innegable entre usos típicos, expresión de estas emociones y ofensa. Ahora bien, los emotivistas incluyen la expresión de la emoción en el significado de términos discriminatorios: "brasuca", por ejemplo, significaría desde esta perspectiva "término expresivo de desprecio hacia los brasileños" o "término expresivo de compromiso con perspectiva negativa hacia los brasileños". La expresión de emociones negativas a su vez justifica la ofensa del auditorio. Para nosotros, la relación se articula de modo diferente. La conexión no fluye directamente desde la inclinación emotiva codificada en el significado léxico de términos discriminatorios. En su lugar, entendemos que la conexión es indirecta: es porque el término está registrado como [+vulgar, -cortés, +argot, +derogatorio] que se usa para expresar emociones negativas. Las figuras 1 y 2 muestran claramente el punto. 
Para el emotivista, los términos discriminatorios están conectados semánticamente (en el sentido de "pertenecer a su significado-tipo") con emociones negativas. Esta relación está representada por la línea derecha de la figura 1. Ahora bien, estas actitudes y emociones, una vez hechas públicas, son inaceptables, incorrectas desde el punto de vista social y ético, e indudablemente ofensivas. Por lo tanto, la conexión entre actos ofensivos y términos discriminatorios circula desde la línea derecha hacia abajo y después por la línea inferior de derecha a izquierda.

Desde la perspectiva propuesta en este artículo, el flujo es diferente, tal y como se ve en la figura 2: la conexión semántica se ubica en la línea de la izquierda. Los términos singulares son ofensivos en virtud de su significado-tipo, que incluye un nivel uso-teórico. En otras palabras, es la marca de registro lo que hace a la palabra inaceptable y, en virtud de ser [+derogatorio], éticamente cuestionable. Como ley de la psicología humana, aquellos que optan por lo que ética y socialmente son "malas palabras" a menudo lo hacen por albergar actitudes negativas. Por consiguiente, en nuestra teoría, la conexión entre términos discriminatorios y la expresión de estas emociones circula desde la línea izquierda hacia abajo y después por la línea de abajo, de izquierda a derecha.

\subsubsection{Similitudes con el "prohibicionismo"}

Una observación común a nuestro acercamiento es su similitud con el "prohibicionismo". ${ }^{17}$ De acuerdo con esta teoría, los términos discriminatorios son palabras tabú, términos cuyo uso está socialmente prohibido. Usarlas, entonces, constituye una violación de la norma que nos resulta chocante. Ahora bien, aun cuando consideramos que esta perspectiva es acertada en puntos importantes, difiere de la teoría aquí propuesta en otros.

Para empezar, Anderson y Lepore no consideran la prohibición como parte del significado lingüístico de los términos. Es solamente un hecho político-social para ellos. Además, sin duda, si estuviéramos tratando de caracterizar los términos discriminatorios como portadores del rasgo [+tabú], ambas perspectivas casi serían variantes notacionales: la misma teoría con diferentes nombres. Sin embargo, para la teoría del registro, ser (típicamente) tabú no es un registro, sino un efecto habitual del uso de palabras pertenecientes a ciertos registros ([+vulgar], [+derogatorio] o [+argot]) en contextos conversacionales con ciertas características (presencia de niños, contextos

${ }^{17}$ Véanse Anderson y Lepore 2013a y 2013b. 
profesionales, etc.), en los que estas palabras deben ser evitadas. Es interesante notar cómo, en los contextos adecuados (entre amigos, en conversaciones de corte agresivo), palabras registradas como [+vulgar] o [+argot] no son tabú en lo más mínimo. De la misma manera, en las conversaciones entre miembros de grupos racistas, xenófobos y demás, los términos discriminatorios son esperables y moneda corriente. A modo de ejemplo, compárese: aun cuando es reconocida como [+derogatoria], la palabra "bostero"18 no es considerada tabú entre ciertos fanáticos del fútbol.

\section{Registro y usos distantes}

Nuestra teoría basada en el registro caracteriza a los términos discriminatorios a través de su significado veritativo-condicional y usoteórico: se trata de términos referenciales para grupos humanos en relación de marginación que típicamente poseen rasgos de registro [-cortés, +derogatorio, +argot, +vulgar], lo cual restringe su uso a contextos conversacionales con alta tolerancia a la denigración. De acuerdo con nuestra teoría, estos términos suelen usarse en conversaciones donde el objetivo es denigrar. La apelación a emociones es accesoria: no es esencial para el uso de estos términos en estos contextos, en los que un hablante neutral los usaría de todos modos para encajar en la situación. Asimismo, estas emociones no son parte del significado estable del término.

Este alejamiento de la emoción y el acercamiento al rol del uso en prácticas sociales determinadas es común en términos registrados. Por ejemplo, términos referenciales con rasgo [+infantil] son aceptables y esperados en contextos conversacionales orientados a niños, y padres y educadores los usan en tales contextos para referirse a objetos o procesos cotidianos de forma apropiada. Aun cuando la mayoría de los hablantes en estos contextos sientan amor y ternura por los niños, estos términos en sí no expresan ni comunican de modo alguno estas emociones (pero véase la nota 19). De la misma manera, nadie diría que el uso de "usted" siempre expresa o comunica respeto: nos referimos de esta manera a personas que podríamos incluso despreciar en situaciones que requieren la adopción de este registro.

La teoría del registro puede explicar, por lo tanto, el misterio de los usos distantes de términos discriminatorios. Una manera de mostrar

${ }^{18}$ En Argentina, término [+derogatorio] para referirse a los fanáticos del equipo de fútbol Boca Juniors, que juega con su homofonía parcial con "bosta", término [-formal, +vulgar] que se aplica al excremento bovino. 
cómo podría hacerlo es considerando el uso de términos registrados fuera de sus contextos conversacionales habituales. Los términos registrados no pierden su significado cuando se usan en otros contextos; en particular, no pierden su significado uso-teórico. Esto quiere decir que siguen estando marcados cuando son usados en contextos diferentes al habitual. En consecuencia, su presencia en ellos resulta cuando menos chocante: al escucharlos, el auditorio los siente fuera de lugar, extraños o inadecuados, aun cuando se trate del término correcto desde un punto de vista veritativo-condicional. Examinemos dos ejemplos:

2) Perdón por la demora: mi hijo menor se hizo popó y tuve que cambiarlo de nuevo antes de salir. [En una reunión laboral, un profesional a sus colegas, sin relación de amistad.]

3) Tuve un día de mierda hoy, todo el tiempo con esta neuralgia occipital que me está matando. [En una charla entre amigos muy cercanos.]

En el contexto conversacional donde se emite 2, uno esperaría términos con registro [+cortés, +formal]. En el caso de 3, cabría esperar términos con registro [-cortés, -formal] e incluso [+vulgar] (nótese que "mierda", que es [+vulgar], no se siente fuera de lugar en una conversación de este tipo). La presencia de términos marcados por otro registro ([+infantil] en 2 y [+clínico] en 3) resulta disruptiva en ambos casos. ${ }^{19}$ En el caso de 2 y de 3 , el registro de los términos usados es inadecuado para las situaciones en que se usan, pero aun cuando su uso genere extrañeza, aun así son socialmente aceptables o tolerables. Términos registrados como [+infantil] o [+clínico] pueden

\footnotetext{
${ }^{19}$ No negamos que a menudo el uso transcontextual de términos registrados puede ayudar al hablante a expresar o comunicar algo más allá de lo que dice literalmente. La extrañeza que produce el término fuera de lugar puede disparar, en ciertos casos, una inferencia de corte pragmático que lleva a quienes escuchan a rastrear una segunda intención comunicativa en el hablante. Los términos registrados traen a la mente, en forma inmediata y casi automática, los rasgos principales de sus contextos conversacionales normales. El contraste entre estos rasgos y los del contexto conversacional actual sí pueden ayudar a establecer estas intenciones ulteriores. Así, el oyente en el contexto donde se emite 2 podría inferir que el hablante pretende despertar un sentimiento de cuidado y protección, presentando su condición de vulnerabilidad como defensa ante un acto poco profesional (llegar tarde). De la misma manera, el oyente en el contexto donde se emite 3 podría entender tal vez que el hablante está imitando a su médico en son de burla, o dándole aires de importancia a su dolor de cabeza. Todo esto es consistente con nuestra teoría.
} 
sentirse fuera de lugar sin por ello resultar ofensivos; no justifican una reacción de ofensa. No es éste el caso para todas las categorías de registro. Las palabras marcadas como [+vulgar], por ejemplo, se usan en contextos caracterizados por relaciones sociales de gran intimidad, muy informales y en los que no se aplican reglas de cortesía complejas. Usarlos fuera de estos contextos no sólo resulta chocante, sino ofensivo:

4) Realmente, considero que el trabajo que presentó el doctor es una soberana mierda. [En un congreso de filosofía, un colega a otro (sin ser amigos).]

En un contexto así, el término "mierda" ([-cortés, -formal, +vulgar]) no sólo resulta chocante y fuera de lugar; también puede conducir a que quienes escuchan pidan al hablante que modere su vocabulario, o suscitar miradas desaprobatorias y justificar la ofensa del doctor al que se refiere (y la del público). No es tanto el sentido de la palabra el que genera esta reacción, sino su registro. Por un lado, el uso transcontextual dispara comparaciones entre contextos conversacionales académicos e informales que desvalorizan al primero; por otro, el uso de un término perteneciente a una categoría de registro lleva consigo, independientemente de las intenciones del hablante, la aprobación y el refuerzo de la estructura o práctica social asociada al contexto conversacional habitual. En el caso de términos con registro [+vulgar] en contextos formales, su uso apunta a cerrar la distancia que separa los roles de los participantes y desenmascarar una fachada de formalidad injustificada. Cualquiera de estos actos lingüísticos amenaza el marco social de la situación y, por consiguiente, genera resquemores.

Los usos transcontextuales de términos discriminatorios traen consigo una consecuencia más severa. Puesto que, en su mayoría, estos términos tienen un registro [+vulgar], su uso fuera de contexto acarrea las mismas consecuencias que vemos en 4; la palabra se siente fuera de lugar y resulta amenazante para los lazos establecidos en la situación social donde se use. Por ese motivo, el término resulta ofensivo, y tiende a llevar al auditorio a pedir al hablante que modere su vocabulario; pero hay algo aún más grave que viene de la mano del registro [+derogatorio]:

1) Ahí viene el retrasado.

En la situación con la que empezamos este trabajo, "retrasado" se usaba como apelativo cariñoso entre amigos. Ahora bien, aunque 
en esta circunstancia esté claro que no existe intención de expresar emociones negativas (recordemos que los hablantes son personas con capacidades cognitivas diferentes), aun así el término sigue resultando chocante, desvalorizador. El uso de términos con registro [+derogatorio], incluso en casos de uso transcontextual, aprueba y refuerza el entramado social del contexto conversacional originario del término. De nuevo, esto no es privativo de esta marca de registro: recordemos que el uso de términos con registro [+infantil] avala el trato diferencial a niños allí donde se usen. Cuando se trata de términos con registro [+derogatorio], lo que se avala es el trato discriminatorio. Por lo tanto, aun sin intención del hablante, llamar "retrasado" a alguien avala indirectamente la idea de que las personas con capacidades cognitivas diferentes merecen ser identificadas sobre la base de ese rasgo y denigradas en virtud del mismo. Usar el término refuerza un contexto sociopolítico complejo donde se considera que personas con estas características son "inferiores" respecto del grupo considerado como "normal" y, por consiguiente, merecedoras de un trato social y económico subóptimo. Esto corre también para términos con registro [+derogatorio] que no clasificaríamos como discriminatorios:

5) Lamento mucho escuchar que su marido está pasando por una situación tan severa. Déjeme darle el teléfono de un loquero, tal vez ahí puedan ayudarlo a aliviarse. [En una cena de negocios, dos colegas.]

"Loquero", un término [+derogatorio] para personas o instituciones al servicio de la salud mental, resulta chocante en este contexto. No se trata de un término [+vulgar], pero aun así el auditorio puede considerar que la elección de palabras deja que desear (o que el hablante está siendo insultante e irónico), en virtud del hecho de que el término denigra a estas instituciones y, por ende, a sus pacientes. Lo que resulta molesto es la aprobación implícita del hablante de la banalización de los desórdenes de la salud mental, aprobación que viene de la mano de la elección de la palabra. Nótese que posibles reacciones del auditorio indicarían un desacuerdo metalingüístico con el uso de la palabra, basado en el refuerzo de la necesidad de respetar y valorar debidamente a estos trabajadores, instituciones y pacientes.

Así, los términos discriminatorios, usados en forma distante, no sólo resultan chocantes e inaceptables por su registro [-cortés, +vulgar]; también son éticamente cuestionables para quienes consideramos que el entramado social originario es injusto y poco inclusivo. 


\section{Conclusión}

La estrecha asociación entre el uso típico de términos discriminatorios para expresar emociones o actitudes negativas hacia personas pertenecientes a grupos en relación de opresión o marginación y el grado de ofensa que generan en el auditorio ha llevado a muchos autores a darle un papel preponderante a la primera en el significado de estos términos. Así, diferentes teorías han codificado esta expresión como parte del significado estable de estos términos, o como parte del mensaje comunicado por su uso. El punto tiene un sólido asidero: estos términos son usados prototípicamente por personas que albergan estas emociones y desean hacerlas públicas.

No obstante, consideramos que el fenómeno de los usos distantes de estos términos nos lleva a una explicación alternativa. El hablante y el auditorio interpretan claramente los usos distantes como alejados de la expresión de emociones usuales: se trata de términos discriminatorios usados como apelativos cariñosos, como insultos para otros grupos, casos de producción forzada y otros. En todos ellos, empero, la palabra sigue pareciendo ofensiva, cargada de algo que no está bien. Nuestra propuesta es entender que el rasgo característico de estos términos, que los hace merecedores de desaprobación incluso en estos usos, es su marca de registro.

El concepto sociolingüístico de registro está subutilizado en la filosofía del lenguaje. Sin embargo, la comparación de estos usos distantes con otros casos de usos transcontextuales de términos registrados de diferentes tipos permite identificar facetas comunes que, tomadas en conjunto, contribuyen a explicar por qué los términos discriminatorios son siempre, en cierta medida, inadecuados e inaceptables. ${ }^{20,21}$

${ }^{20}$ Queremos recordar con este artículo a Maite Ezcurdia. Además de que Maite fue y será una de las voces más importantes en la filosofía latinoamericana, guarda también un espacio especial en la vida de los dos autores, como amiga y como interlocutora. A ella entonces, puesto que habría disfrutado de la discusión tanto como nosotros, va dedicado este texto.

${ }^{21}$ El presente trabajo fue realizado gracias al apoyo del Social Sciences and Humanities Research Council (Canada), a través del Subsidio de Investigación otorgado al doctor Stainton. Versiones anteriores y fragmentos de este trabajo fueron presentados en el Workshop ICSO IV (Sociedad Argentina de Análisis Filosófico, Buenos Aires, Argentina, 2018), en el Departamento de Lingüística y Estudios Vascos (Universidad del País Vasco, País Vasco, 2018), en el VI Davis Philosophy Extravaganza (DEX) (University of California-Davis, 2018), en el XI Congreso Centroamericano de Filosofía (Universidad de Panamá, 2018). Versiones previas y revisadas de este trabajo fueron presentadas también en el Departamento of Filosofía, University of Calgary (2019) y en el Departamento de Filosofía de Carleton University (2019). Agradecemos a todos los participantes a estos eventos por sus 


\section{BIBLIOGRAFÍA}

Anderson, L. y E. Lepore, 2013a, "What Did you Call Me? Slurs as Prohibited Words", Analytic Philosophy, vol. 54, no. 3, pp. 350-363.

—_, 2013b, "Slurring Words", Nô̂s, vol. 47, no. 1, pp. 25-48.

Austin, J.L., 1962, How to Do Things with Words, Clarendon Press, Oxford. [Versión en castellano: Cómo hacer cosas con palabras, trad. Genaro Carrió y Eduardo Rabossi, Paidós, Barcelona, 1982.]

Bernal, M., 2008, "¿Insultan los insultos? Auténtica descortesía vs. Descortesía no auténtica en español coloquial", Pragmatics, vol. 18, no. 4, pp. 775-802.

Camp, E., 2013, "Slurring Perspectives", Analytic Philosophy, vol. 54, no. 3 , pp. 330-349.

Croom, A.M., 2011, "Slurs", Language Sciences, vol. 33, pp. 343-358.

Diaz-Legaspe, J., 2020, "What Is a Slur?", Philosophical Studies, vol. 177, no. 5, pp. 1399-1422.

Diaz-Legaspe, J., C. Liu y R.J. Stainton, 2020, "Slurs and Register: A Case Study in Meaning Pluralism", Mind and Language, vol. 35, no. 2, pp. 156-182.

Gregory, M., 2001, Communication in Linguistics, Éditions du GREF, Toronto.

Gregory, M., 1967, “Aspects of Varieties Differentiation", Journal of Linguistics, vol. 3, no. 2, pp. 177-274.

Halliday, M.A.K., 1973, Explorations in the Functions of Language, Edward Arnold, Londres.

Halliday, M.A.K. y C.M.I.M. Matthiessen, 2004, An Introduction to Functional Grammar, 3a. ed., Edward Arnold, Londres.

Hom, C., 2012, "A Puzzle about Pejoratives", Philosophical Studies, vol. 159 , no. 3, pp. 383-405.

—_, 2010, "Pejoratives", Philosophy Compass, vol. 5, no. 2, pp. 164185.

— 2008, "The Semantics of Racial Epithets", Journal of Philosophy, vol. 105, no. 8, pp. 416-440.

Hom, C. y R. May, 2018, "Pejoratives as Fiction", en Sosa 2018, pp. 108131.

- 2013, "Moral and Semantic Innocence", Analytic Philosophy, vol. 54, no. 3, pp. 293-313.

Hornsby, J., 2001, "Meaning and Uselessness: How to Think about Derogatory Words", Midwest Studies in Philosophy, vol. 25, no. 1, pp. 128141.

Jeshion, R., 2013a, "Expressivism and the Offensiveness of Slurs", Philosophical Perspectives, vol. 27, no. 1, pp. 231-259.

comentarios. Agradecemos también a los árbitros de la revista por sus comentarios y sugerencias. 
Jeshion, R., 2013b, "Slurs and Stereotypes", Analytic Philosophy, vol. 54, no. 3, pp. 314-329.

Labov, W., 1972, Language in the Inner City: Studies in the Black English Vernacular, University of Pennsylvania Press, Filadelfia.

Mugford, G., 2008, "How Rude! Teaching Impoliteness in the Second Language Classroom”, ELT Journal, vol. 62, no. 2, pp. 375-379.

Nunberg, G., 2018, "The Social Life of Slur", en D. Fogal, D. Harris y M. Moss (comps.), New Work on Speech Acts, Oxford University Press, Oxford, 2018.

Potts, C., 2007, “The Expressive Dimension", Theoretical Linguistics, vol. 33, no. 2, pp. 165-198.

Predelli, S., 2013, Meaning without Truth, Oxford University Press, Oxford.

Pullum, G. K., 2018, "Slurs and Obscenities: Lexicography, Semantics, And Philosophy", en Sosa 2018, pp. 168-192.

Schlenker, P., 2007, "Expressive Presuppositions", Theoretical Linguistics, vol. 33, no. 2, pp. 237-245.

Sosa, D. (comp.), 2018, Bad Words, Oxford University Press, Oxford.

Stainton, R., 1999, "Interrogatives and Sets of Answers", Crítica. Revista Hispanoamericana de Filosofía, vol. 31, no. 91, pp. 75-90.

Whiting, D., 2013, “It's Not What You Said, It's The Way You Said It: Slurs and Conventional Implicatures", Analytic Philosophy, vol. 54, no. 3, pp. 364-377.

Williamson, T., 2009, "Reference, Inference, and the Semantics of Pejoratives", en J. Almog y P. Leonardi (comps.), The Philosophy of David Kaplan, Oxford University Press, Oxford.

Zimmermann, K., 2003, “Constitución de la identidad y anticortesía verbal entre jóvenes masculinos hablantes de español", en Actas del Primer Coloquio del Programa EDICE, Universidad de Estocolmo, Estocolmo.

Recibido el 14 de agosto de 2018; revisado el 2 de noviembre de 2019; aceptado el 11 de noviembre de 2019. 